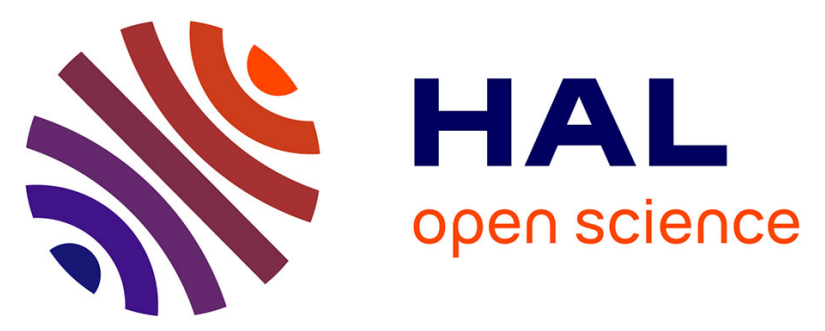

\title{
Automation System Development for Micrograph Recognition for Mineral Ore Composition Evaluation in Mining Industry
}

\author{
Olga E. Baklanova, Olga Shvets, Zhanbai Uzdenbaev
}

\section{- To cite this version:}

Olga E. Baklanova, Olga Shvets, Zhanbai Uzdenbaev. Automation System Development for Micrograph Recognition for Mineral Ore Composition Evaluation in Mining Industry. 10th IFIP International Conference on Artificial Intelligence Applications and Innovations (AIAI), Sep 2014, Rhodes, Greece. pp.604-613, 10.1007/978-3-662-44654-6_60 . hal-01391367

\section{HAL Id: hal-01391367 \\ https://inria.hal.science/hal-01391367}

Submitted on 3 Nov 2016

HAL is a multi-disciplinary open access archive for the deposit and dissemination of scientific research documents, whether they are published or not. The documents may come from teaching and research institutions in France or abroad, or from public or private research centers.
L'archive ouverte pluridisciplinaire HAL, est destinée au dépôt et à la diffusion de documents scientifiques de niveau recherche, publiés ou non, émanant des établissements d'enseignement et de recherche français ou étrangers, des laboratoires publics ou privés.

\section{(c)(1)}

Distributed under a Creative Commons Attribution| 4.0 International License 


\title{
Automation System Development For Micrograph Recognition For Mineral Ore Composition Evaluation In Mining Industry
}

\author{
Olga E. Baklanova, Olga Ya.Shvets and Zhanbai Uzdenbaev \\ D.Serikbayev East-Kazakhstan State Technical University, Ust-Kamenogorsk, The Republic \\ Kazakhstan \\ 0_E_Baklanova@mail.ru, oShvets@ektu.kz, ZhUzdenbaev@ektu.kz
}

\begin{abstract}
The article deals with the problem of micrographs automated obtaining and micrographs automated processing ore samples of ore dressing processes in ferrous metallurgy. It is described the task of interpreting the results and interaction subsystem automated obtaining and automated processing of samples of ore mining micrographs and beneficiation processes ferrous metals, used to analyze the quality of mineral rocks with other automation systems. It is defined specifies requirements for the subsystem micrographs analysis.
\end{abstract}

Keywords. Petrographic analysis, Digital microscopy system, Image recognition, Computer vision, SCADA system.

\section{Introduction}

Petrography is the science that studies the material composition of the rocks. Unlike minerals, rocks are aggregates composed of different minerals [1]. Minerals are homogeneous in composition and structure of the rocks and ores. They are natural chemical compounds resulting from various geological processes. Historically minerals initially determined by color and shape.

Some mining and processing enterprise mixed ore from several fields. In this case it is important to determine the mixing ratio. It is necessary to find a mineral composition of the ore, which can be determined by optical microscopic analysis. In some enterprises, it is implemented manually by technologist-mineralogist.

Nowadays, some complexes micrographs analyzed manually locally in the enterprise by technologist - mineralogist, or in the center of the head group of companies with the transition to the Internet or other communication channels. Manual analysis has drawbacks such as dependency from psychophysiological properties of laboratory specialist (human factor) and the long duration of treatment of one of the micrograph. But the process of analyzing ore micrographs can be automated and implement it locally in the enterprise, due to the fact that subsystem micrographs analysis oriented to samples of a particular ore easier to create than a universal program for quantitative analysis of samples of any material [2].

There are the following automation tasks from all at mining complexes: 
- Automated obtaining of micrographs;

- Quantitative analysis of mineral ore samples by micrographs.

\section{Materials and Methods}

\subsection{Methods of Automated Acquisition of Mineral Rocks Images}

It is required for automated obtaining of micrographs automated microscope containing a motorized specimen stage, a mechanism to change the filters, focusing mechanism, a revolver change lenses [3].

Typically, in this case it is supposed to use the manufacturer's software, which is responsible for the control for motorized units of microscope. Simplified classification of microscopy cameras is shown in Figure 1. Preferably use trinocular microscope with a camera that does not require an optical adapter with a digital interface USB, controlled by a computer and with the TWAIN support.

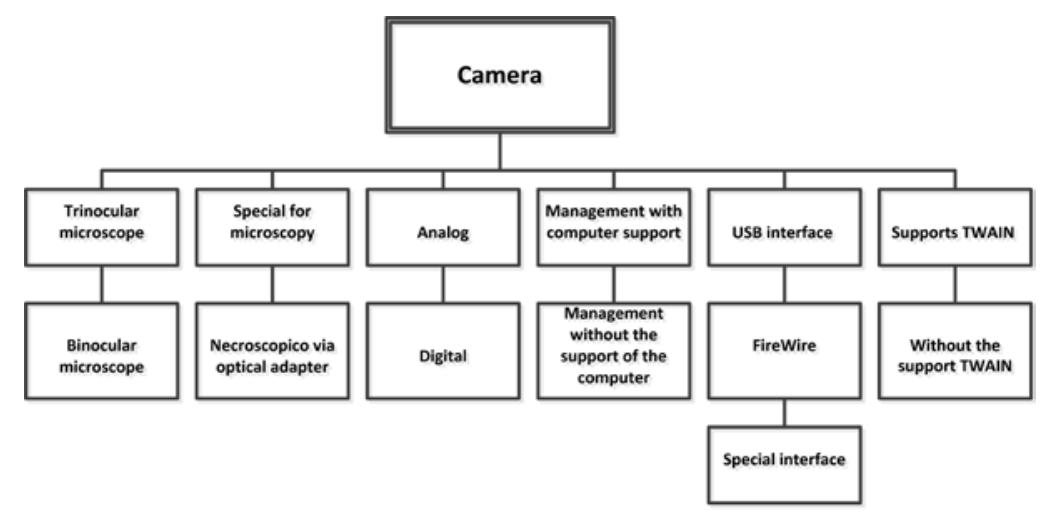

Fig. 1. Classification of microscopy cameras

Thus, the process of obtaining images can pass without operator as in the case of a fully automated microscope and with the participation of the operator. In the case of automated microscope software fully controls the microscope, after getting photo in the memory of a computer program for image analysis starts. It is required from analysis program that the results were collected to a database accessible over the LAN. From database, these results will be perceived by SCADA- system, and the system makes decisions.

In the case of partially automated or non-automated microscope operator is responsible for changing the samples, the selection of the microscope objective, take a photo on your computer, run the program and image analysis. As in the previous case, the analysis program is required to enter the results into a database, where SCADAsystem can use it, and the system makes decisions.

This paper describes the problem of optical microscopy analysis on the mining complex. It is determined the requirements for obtaining and analyzing subsystem 
micrographs. The most important of them is the requirement to the camera, the serial processing micrographs of various samples of ore analysis program should each segment micrograph segmentation method has been proposed, then point of interest must be identified as certain minerals, the quality of the segmentation is more significant than the processing of a single image, the program should transmit the results of its work to the database [4].

Theoretically possibility to determine the mineral ore targets on the microscopic image substantiated by author M.P. Isayenko [5].

\subsection{Methods of Automated Processing of Mineral Rocks Images}

Very often different minerals on the micrographs correspond to objects of different types of shapes and colors. This allows the identification of various minerals in the form and color of objects. In some cases, also take into account the polarization of certain minerals sample [6, 7].

In this case, it is necessary to make several pictures, accompanying it by turning the sample. Consider a sample of slag copper anode as an example (Figure 2). Micrographs of this sample were kindly provided Eastern Research Institute of Mining and Metallurgy of Non-ferrous Metals (Kazakhstan, Ust-Kamenogorsk).

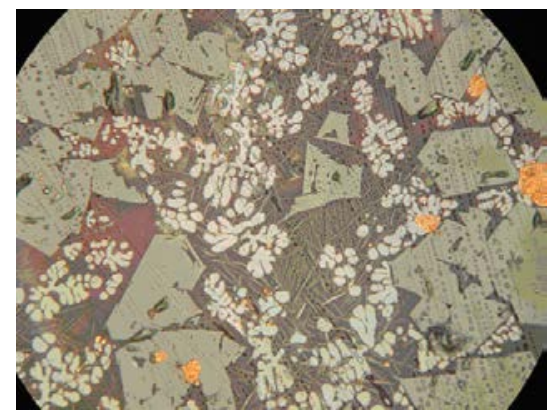

Fig. 2. Micrograph of a sample of slag copper anode, increasing in 500 times

According to experts on microscopy of minerals from Eastern Research Institute of Mining and Metallurgy of Non-ferrous Metals at this picture there is no minerals having dependent on the direction of the plane of polarization of light. In this picture you can detect metallic copper and the following minerals: cuprite $\mathrm{Cu} 2 \mathrm{O}$, magnetite Fe3O4, Delafosse CuFeO2, silicate glass.

Cuprite $\mathrm{Cu} 2 \mathrm{O}$ can be identified as follows: it is characterized by the shape of a round shape, color - it is light gray (sometimes with a slight bluish tint). Figure 3 shows the graphical representation of cuprite.

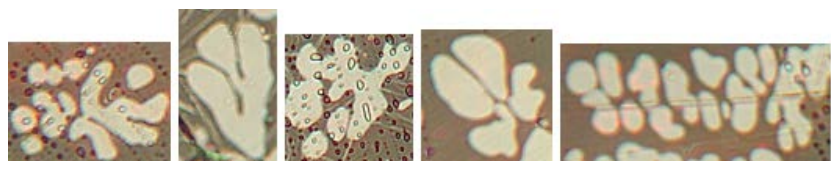

Fig. 3. Cuprite on micrographs 
Fe3O4 magnetite on micrographs may also be detected by color and shape. Color of magnetite on micrographs is dark gray. Shape is angular, as expressed by technologists, "octahedral". Figure 4 shows magnetite apart from other minerals picture.

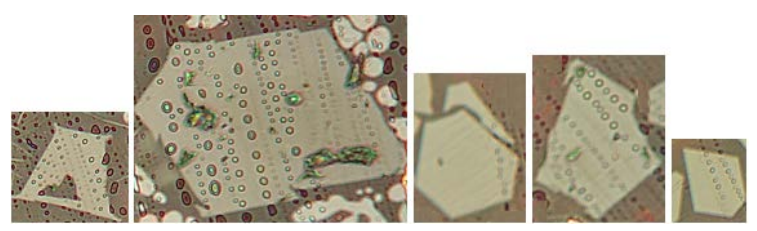

Fig. 4. Magnetite on micrographs

Delafossite $\mathrm{CuFeO} 2$ micrographs can allocate to the needle shape and gray (with a brownish tint) color. On Figure 5 it can be seen delafossite on the micrographs

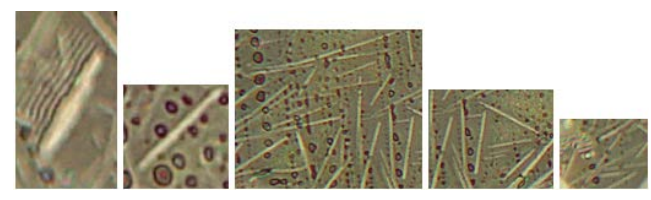

Fig. 5. Delafossite on micrographs

Metallic copper on the micrographs can be found on the following criteria: color yellow, shape - round, without flat faces. Figure 6 represents a micrograph metallic copper

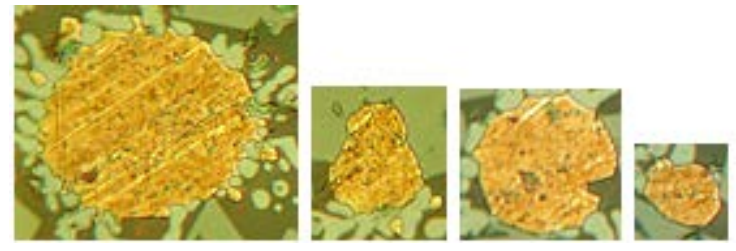

Fig. 6. Metallic copper on micrographs

Silicate glass - is a dark gray mass fills the rest of the space that is left of the other minerals.

These data indicate that for real micrographs slag samples (and some other minerals) it is possible to use automated qualitative assessment of the mineral composition.

After receiving the full image it is often needed to treat it, mainly to simplify further analysis. Available processing capabilities are as follows:

- color correction / color control;

- sharper image display of objects;

- contrast enhancement;

- contrast or inversion;

- alignment of images;

- mosaics;

- correction of spherical aberration; 
- morphological filters.

Figure 2 processing by morphological dilation filter and effects of some morphological filters can be viewed on Figure 7 [9].

Basically, image processing is required because of the need to simplify the process of analysis and / or to improve visual perception of the operator-mineralogist [10].

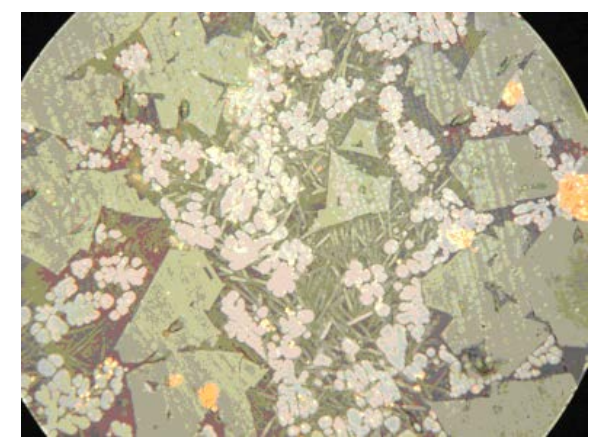

Fig. 7. Micrograph of slag copper anode after 6 times of the use of morphological dilation

Any micrograph can be described in different color spaces. Usually, transformation into another color space is used to segment the micrograph particular method. Known space RGB (red, green, blue), YCrCb (brightness, hue, and saturation ), YIQ ( brightness, hue, saturation ), L*a*b* CIE 1976 (takes into account the human perception of color), $\mathrm{L}^{*} \mathrm{C}^{*} \mathrm{H}^{*}$ ( psychometric brightness, hue and saturation ), HSI ( hue, saturation , brightness), HSL (hue, saturation , lightness), L*u* ${ }^{*}$ CIE 1973 (equal contrast color space) [4].

Micrographs analysis suggests image segmentation, classification of found objects and calculating the percentage ratio of each type of object. It can provide such a method of segmentation as color segmentation. The user determines what colors correspond to certain types of objects, which are created on the basis of the color clusters. Micrograph segment to be allocated may not contain all the colors of the cluster, but includes most of these colors. Micrograph is divided on contours according to the information of the color clusters.

As a criterion for shape analysis it can be suggested the following. Selected contour is transferred to the Cartesian coordinate system. Then, from the bottom left point after some distance is drawn straight to the point of standing up and to this line is constructed perpendicular and calculated angle perpendicular. It would be considered the first perpendicular. Next contour is gone by the same way clockwise. Next perpendicular constructed similarly. The absolute value of the difference between the angle of each of the current and preceding perpendicular will be remembered by the program.

When all of the perpendiculars will be built program adds all absolute difference values of angles and divides it to the length of their boundary contour formed by segments, which was perpendicular. Cuprite calculated value for the relative rotation angle correlated to the length of the contour composed segments, which was perpendicular, is more than for magnetite. Method can be very sensitive to random points of 
the real contour, so you should carefully choose the length of the segments, which are constructed perpendiculars. For each type of object it is required to make the range sum of relative angles values correlated to the length of the contour.

Segmentation is also possible by determining the differences of brightness, color gradients, calculating the area of contours [5].

For analysis micrograph program more qualitative segmentation is override the minimum analysis time of one micrograph. It also requires a serial processing of multiple images ore samples.

The analysis result of a micrograph is a table in the same column indicates the name of a mineral in the other relative area occupied by them in the micrograph. Also there are specifies the identity of the image, such as the name of the field, the number of test samples, the number of files in a batch of samples.

\section{$3 \quad$ Results and Discussion}

Feature optical microscopic analysis is the percentage of minerals detected on the surface of the sample may be different from the ratio, identified by chemical analysis. This is due to the fact that a picture of the sample surface cannot be analyzed, but it can be different from that on the surface. Therefore it is necessary to analyze more than one ore sample and calculate the percentage of minerals in several pictures. Next SCADA- system calculates the corrected value ratios of minerals in the ore [11].

Interpretation of the results is required due to the fact that the quality measures adopted by the mining industry cannot be directly obtained as a result of analysis techniques. I.e. there are input data as a percentage of a certain type of objects. It is required to interpret these data to obtain quality indicators adopted in the enterprise. Since the quality criteria against mining products in the enterprise depend on the ore and technology enterprise, the system should provide the ability to customize rules interpretation.

Interpretation rules include some mathematical and logical operations. Speed is important. It is required to accept the interpretation of the rules on the basis of the SCADA-system applicability, which has become an integral part of APCS. Image analysis results also include identification data, carrying information about the name of the field and the party ore. The scheme of the flow of information in the automated system of processing of the image to evaluate the qualitative composition of mineral rocks is shown on Figure 8.

Let us consider implementing storage of analysis results. Imaging results of microscopic images are stored in databases. Each field has its own table in the database. This is due to the fact that a single table for the different fields can be unjustified, as the number of allocated objects on microscopic images for a variety of fields may be different. Results interpretation system would be a database, and a shell, leading these databases. 


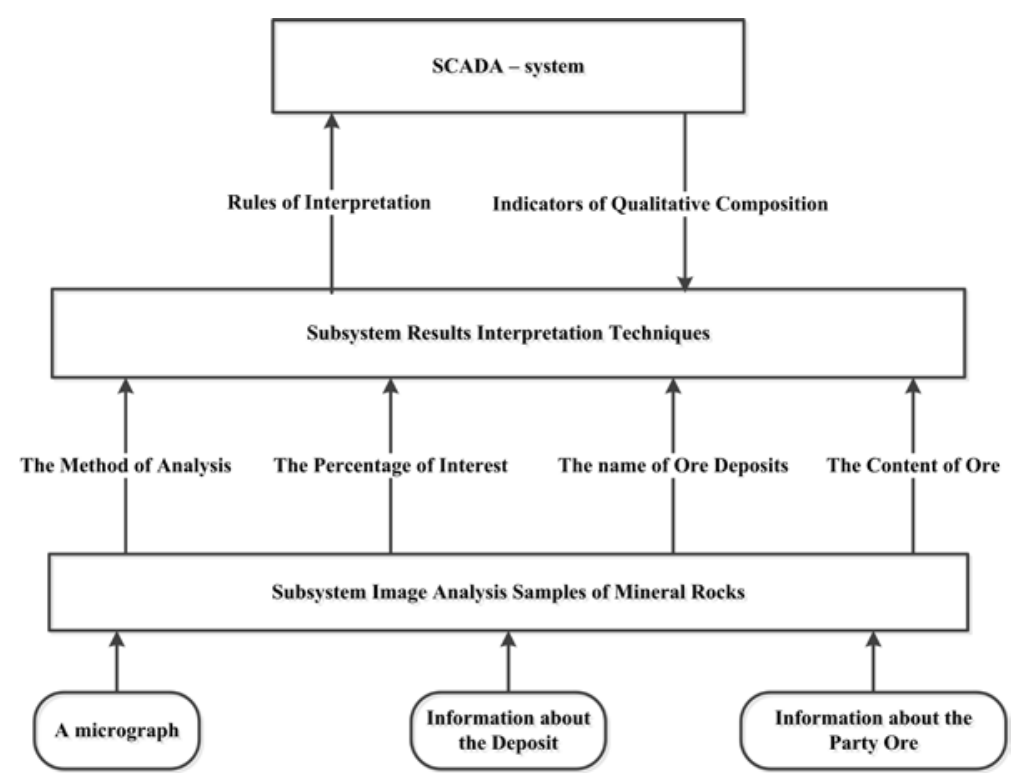

Fig. 8. The scheme of the flow of information in the automated system of processing of the image to evaluate the qualitative composition of mineral rocks

It can be used in multiple tables within a single database. Each source image corresponds with own table. Each table contains information such as the maintenance of a certain color and morphology, identification of mineral rock party. Example of a table for one field is shown on Figure 9.

\begin{tabular}{|c|c|c|c|c|c|}
\hline $\begin{array}{l}\text { Identification } \\
\text { data of party }\end{array}$ & $\begin{array}{c}\text { Object } \\
\mathbf{1}\end{array}$ & $\begin{array}{c}\text { Object } \\
\mathbf{2}\end{array}$ & $\begin{array}{c}\text { Object } \\
\mathbf{3}\end{array}$ & $\boldsymbol{\cdots}$ & $\begin{array}{c}\text { Object } \\
\mathbf{N}\end{array}$ \\
\hline $\begin{array}{l}\text { AMIRKN11212 } \\
2010112\end{array}$ & $6 \%$ & $3 \%$ & $8 \%$ & $\cdots$ & $\mathrm{Z} \%$ \\
\hline$\cdots$ & & & & & \\
\hline & & & & & \\
\hline
\end{tabular}

Fig. 9. Identification of mineral rock party

The most obvious solution to the problem of interpretation of the rules will be use to build support scripting subsystem in interpreting the results. For this purpose scripting languages were considered for claims processing speed, ease of syntax, prevalence, the ability to integrate into the overall system.

Input interpretation subsystem in this case composed of the main attributes such as:

- type of treatment - planimetric method or Delesse-Rozival;

- internal identifying name of the object and percentage;

- information on the name field, she entered during the setup phase of the source image;

— identification number of the party ore, it is removed from the file names. 
Also it is possible to change the interpretation or clarification of the rules by transferring them from the SCADA-system.

It was analyzed the most common languages Python, Ruby, Perl. However, these scripting languages have not satisfied the required specification [11-13]. Next, it was considered possible solutions to the problem, based on scripting languages by going to rule language of embedded scripting languages SCADA-systems.

Using a scripting language built into SCADA-system, it is convenient that the technical staff of enterprises has gained considerable experience in dealing with them, which means less time debugging rules interpretation.

Table 1 shows a comparison of SCADA-systems according the presence of the scripting language. For comparison, we have used some common SCADA-system.

Table 1. Comparison of SCADA-systems according the presence of a scripting language

\begin{tabular}{|c|c|c|}
\hline $\begin{array}{c}\text { Name of SCADA- } \\
\text { system }\end{array}$ & $\begin{array}{c}\text { Presence of built script- } \\
\text { ing language }\end{array}$ & Name of built scripting language \\
\hline Genesis 32 & yes & $\begin{array}{c}\text { Visual Basic for Applications, JScript, } \\
\text { VBScript }\end{array}$ \\
\hline InTouch & yes & QuickScripts \\
\hline Citect & yes & CiCode, CitectVBA. \\
\hline TraceMode & yes & $\begin{array}{c}\text { Control algorithms based on language of } \\
\text { IEC 61131-3 standard }\end{array}$ \\
\hline MasterSCADA & yes & Propriety on 150 functions \\
\hline iFix & yes & Visual Basic for Applications \\
\hline Advantech Studio & yes & Propriety on 100 functions \\
\hline GeniDAQ & yes & BasicScript, identical VBA \\
\hline WinCC & yes & Visual Basic for Applications, ANSI-C \\
\hline
\end{tabular}

Most SCADA-systems support the use of Visual Basic for Applications 6.x. Regarding the solution of the problem it is appropriate to use Visual Basic for Applications, as it is available in the script editor of leading SCADA-systems, which is the reason that the technical staff are well acquainted with the language.

An important requirement is to ensure the transfer of the results of image processing micrographs mineral rocks in SCADA-system with the speed with which the act interpreted results of treatment.

It was considered existing technologies and exchange of data between different applications used in process automation OLE for Process Control (OPC) [10], [17], [18]. It was analyzed OPC DA, OPC AE, OPC Batch, OPC DX, OPC HDA, OPC Security, OPC XML-DA, OPC UA. In all of these (Table 1) SCADA-systems standards implemented OPC DA and the vast majority of systems OPC HDA.

Exchange of information with superior enterprise systems can be implemented by standard OPC DA - it should be considered an automated image processing system as several pseudo sensors, the number of which is determined by the number of image sources. Scheme of interaction between source and receiver data is shown on Figure 10. 


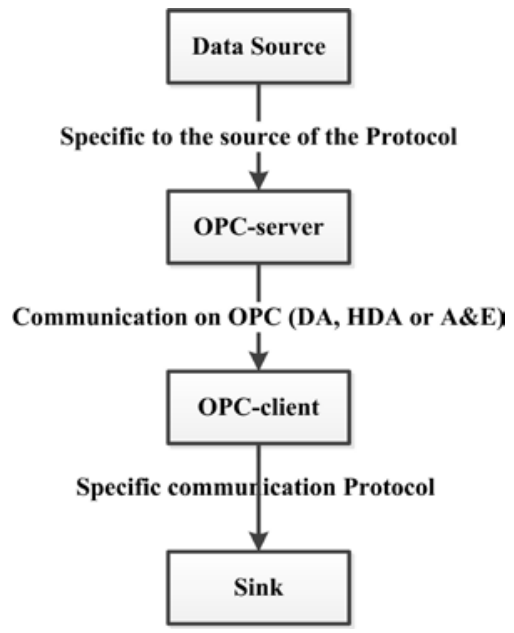

Fig. 10. Scheme of interaction between source and receiver data

Standard OPC DA implements the transfer of three types of attributes; it is a variable, the value and time of receipt of the data.

Based on the aforementioned arguments, as the basis of information exchange it was recommended OPC DA technology.

\section{Conclusion}

It is described the problem of optical microscopy analysis on the mining complex. It is determined the requirements for obtaining and analyzing subsystem micrographs. The most important of them is the requirement to the camera, the serial processing micrographs of various samples of ore analysis program should each segment micrograph segmentation method has been proposed, then point of interest must be identified as certain minerals, the quality of the segmentation is more significant than the processing of a single image, the program should transmit the results of its work to the database.

It is considered tasks of the interpretation results of the analysis to convert the results of the image processing in accordance with some specified quality requirements. It is analyzed for the interpretation of languages, such as, Python, PERL and Ruby. It is considered a variant of the implementation language interpretation rules based on the syntax of Visual Basic for Applications as a scripting language with a rather simple syntax. Among the possible ways to implement the technology options were considered OLE for Process Control (OPC) and CORBA.

Further research should be focused on the development of methods and algorithms by which can be automated solving phase analysis of samples of mineral rocks. In order to define a class of algorithms and techniques required to make a list of functions "universal" system, which allows automates key tasks of microscopy. Also, the system should be implemented data transmission module to higher systems. 


\section{References}

1. Harvey, B., Tracy, R.J.: Petrology: Igneous, Sedimentary, and Metamorphic. 2nd ed., New York: W.H. Freeman (1995)

2. Clarke, A. R., Eberhardt, C. N.: Microscopy Techniques for Materials. Science Woodhead Publishing, CRC Press, 459 p. (2002)

3. Panteleev, C., Egorova, O., Klykova, E.: Computer microscopy. Technosphere, 304 p. (2005)

4. Baklanova, O.E.: Development of algorithms for image recognition needed to assess the quality of the mineral species in the mining industry. In: Abstracts of International Conference «Mathematical and Informational Technologies, MIT 2013»,VrnjackaBanja and Budva, September 5-September 14, 2013, pp.63-64. (2013)

5. Isayenko, M. P., Borishanskaya, S. S., Afanasyev, E L.: Keys to the main ore minerals in the reflected light. Moscow: Nedra, 1986, 382 p. (1986)

6. Farndon, J.: The practical encyclopedia of rocks and minerals. How to Find, Identify, Collect and Maintain the World's best Specimens, with over 1000 Photographs and Artworks. London: Lorenz Books (2006)

7. Chris, P.: Rocks and Minerals. Smithsonian Handbooks. New York: Dorling Kindersley, 2002.

8. Shaffer, P. R., Herbert S. Z., Raymond, P.: Rocks, Gems and Minerals. Rev. ed. New York: St. Martin's Press (2001)

9. Gonsales, R. C., Woods, R. E.: Digital image processing. 3rd edition, Pearson Education, 976 p. (2011)

10. Baklanova, O. E., Uzdenbaev, Z.S.: Development of methodology for analysis of mineral rocks in the mining industry. In: Joint issue of the Bulletin of the East Kazakhstan state technical University and Computer technology of Institute of computational technologies, Siberian branch of the Russian Academy of Sciences, Part 1, September, 2013, 60-66 (2013)

11. Python vs C++ comparison. - [Electronic resource]. - Mode of access http://shootout.alioth.debian.org/u32/benchmark.php?test=all\&lang=python\&lang2=gpp\& box $=1$

12. Ruby vs C++ comparison. [Electronic resource]. - Mode of access http://shootout.alioth.debian.org/u32/benchmark.php?test=all\&lang=yarv\&lang2=gpp

13. PERL vs $\mathrm{C}++$ comparison. - [Electronic resource]. - Mode of access http://shootout.alioth.debian.org/u32/benchmark.php?test=all\&lang=perl\&lang2=gpp

14. Moskalev, A.A.: CORBA in industrial applications. In: World com-computer automation (On-line), N5, 2001.- [Electronic resource]. - Mode of access http://www.mka.ru/?p=42049 (2001)

15. Object Management Group: “The Common Object Request Broker: Architecture and Specification”, Version 2.5 September 2001. www.omg.org (2001)

16. Schmidt, D. C., Kuhns, F.: An Overview of the Real-Time CORBA Specification. In: IEEE Computer, pp. 56-63, June, 2000 (2000)

17. Grigoriev, A.: Standard OPC path to integrate disparate systems, part 1. In: PC Week/RE, $\mathrm{N}$ 32, 2001.- [Electronic resource]. - Mode of access http://www.pcweek.ru/industrial/article/detail.php?ID=58992 (2001)

18. Grigoriev, A.: Standard OPC path to integrate disparate systems, part 2, In: PC Week/RE, $\mathrm{N}$ 33, 2001. - [Electronic resource]. - Mode of access http://www.pcweek.ru/industrial/article/detail.php?ID=59064 (2001) 